\title{
An evaluation of the hierarchical factor structure of the Persian-translated death anxiety scale in nursing students of Iran
}

\author{
Hamid Sharif Nia ${ }^{1}$, Rebecca H. Lehto ${ }^{2}$, Saeed Pahlevan Sharif ${ }^{3}$, Amir Hossein Goudarzian*4, Stephanie Sandanasamy ${ }^{5}$, \\ Ameneh Yaghoobzadeh ${ }^{6}$, Azar Jafari ${ }^{4}$ \\ ${ }^{1}$ School of Nursing and Midwifery Amol, Mazandaran University of Medical Sciences, Sari, Iran \\ ${ }^{2}$ College of Nursing, Michigan State University, Michigan, United States \\ ${ }^{3}$ Taylor's Business School, Taylor's University Malaysia, Subang Jaya, Malaysia \\ ${ }^{4}$ Student Research Committee, Mazandaran University of Medical Sciences, Sari, Iran \\ ${ }^{5}$ School of Pharmacy, Taylor's University, Subang Jaya, Malaysia \\ ${ }^{6}$ School of Nursing and Midwifery, Tehran University of Medical Sciences, Tehran, Iran
}

Received: November 19, 2019

Accepted: January 9, 2020

Online Published: February 18, 2020

DOI: $10.5430 /$ jnep.v10n5p23

URL: https://doi.org/10.5430/jnep.v10n5p23

\begin{abstract}
Background/Objective: Clinical nurse educators globally have recognized the prominent necessity of evaluating for death anxiety in students, and adopting curriculum that provides education about death and dying. Reliable assessment tools are needed to evaluate death anxiety in the student population. The study evaluates the hierarchical factor structure of the Persian-translated Templer's Death Anxiety Scale (TDAS) in nursing students from Iran.

Methods: A repeated measures standard psychometric analysis was conducted. In total 400 undergraduate and graduate nursing students from a major university campus in Sari, Iran finished the Persian translated 15-item TDAS. Construct validity was assessed. Reliability was tested using Cronbach's Alpha $(\alpha)$, Theta $(\theta)$, and McDonald's Omega $(\Omega)$ coefficients.

Results: Exploratory factor analysis $(\mathrm{N}=200)$ indicated the TDAS had two factors (Fear of loss of life; Fear to face death). Model fitness indicators confirmed two independent TDAS structure levels. The Cronbach's alpha, Theta, McDonald, and construct reliability were larger than .70 .

Conclusions: Study outcomes corroborated acceptable psychometric properties and factor structure for the TDAS in a sample of Iranian nursing students. Findings suggest that the scale can be utilized for reliable and valid educational evaluation of death anxiety in Iranian nursing students.
\end{abstract}

Key Words: Psychometric, Templer's death anxiety scale, Death, Anxiety, Death education, Nursing students

\section{INTRODUCTION}

Death anxiety is an aversive psychological occurrence that commonly manifests in relation to the proximity of death or the perceived prospect of dying. ${ }^{[1]}$ Clinical nurses are reminded of death by exposures to the suffering and death of patients they serve. ${ }^{[2]}$ Such exposures often trigger death anxiety which may undermine effective emotional health and adaptive coping with such stressors if not addressed. ${ }^{[2,3]}$

\footnotetext{
* Correspondence: Amir Hossein Goudarzian; Email: amir_sari@yahoo.com; Address: Student Research Committee, Mazandaran University of Medical Sciences, Sari, Iran.
} 
Although a wide expansive literature has described the significance of death anxiety assessment across cultures, there remain challenges in nursing education given the lack of validated tools to evaluate the phenomenon in clinical environments.

\section{Background and significance}

Student nurses, recognized to be a group who are vulnerable to stress, have early encounters that may evoke death anxiety during clinical experiences, laboratory simulation, and in course didactic. ${ }^{[2,3]}$ Studies have indicated that mental health symptoms such as anxiety and depressive symptoms are significant in nursing students, factors that are also associated with stress and the presence of death anxiety. ${ }^{[4-6]}$ Clinical nurse educators have recognized the importance of assessing for death anxiety, and adopting curriculum that provides education about death and dying. ${ }^{[7,8]}$ There is also an increasing emphasis on burnout and compassion fatigue, emotional exhaustion and reduced work-related motivation that occurs secondary to ongoing exposures to patients who are experiencing trauma and suffering, among clinicians and nursing students in the provision of care for patients facing life threatening illness. ${ }^{[9-11]}$ Such research has recognized the impact of self-awareness and regulation in management of work-related stressors. ${ }^{[12]}$ Although compassion fatigue and burnout are recognized as contributing to lowered professional quality of life and other negative outcomes, these outcomes have not been examined in relation to death anxiety. ${ }^{[13,14]}$

Multiple factors may affect nurses' attitudes towards death Such attitudes are often formed early in life as a result of socialization, cultural values, religious beliefs, personal deathrelated experiences, and spirituality. ${ }^{[15,16]}$ Death attitudes and personal attributes including age, gender and health circumstances also impact the development of death anxiety. ${ }^{[15,16]}$

Valid and reliable methodologies to quantify death anxiety in global populations of relevance are essential. Templer was an early pioneer in the field of death anxiety research, contributing to a large body of work over the past several decades after development and validation of the Templer Death Anxiety scale (TDAS). ${ }^{[17]}$ Given findings of strong psychometric properties following translation to non-English languages, the TDAS has been translated into Persian and undergone psychometric analysis in both clinical and nonclinical subgroups in the country of Iran. ${ }^{[18,19]}$ These groups included cancer patients, informal family cancer caregivers, and war veterans. ${ }^{[20,21]}$ This early psychometric evaluation provides a platform that established the TDAS as a satisfactory measure to examine potential death anxiety.
Although death anxiety is of strong clinical importance, currently there are few measures to evaluate death anxiety in Iranian nursing students and clinical staff. The availability of death anxiety assessment tools is critical for evaluating the effectiveness of death education curriculum, mental health programs, and targeting interventions. ${ }^{[2]}$ Considering the limited availability of valid and standard instruments in the country of Iran, the focus of the study is to determine the hierarchical factor structure and conceptual underpinnings relative to the Persian version of the TDAS in Iranian nursing students. The hierarchical factor structure refers to the organization of levels including primary, secondary, and tertiary factors of interest that are derived via factor loadings of clustered items and correlation matrices to achieve a coherent interpretation of a construct of interest.

\section{METHODS}

\subsection{Design}

We gleaned our sample size determinants from two sources. Plichta and Kelvin ${ }^{[22]}$ suggested that a minimum sample size for factor analysis should be between five to ten times the instrument item numbers. MacCallum and Widaman ${ }^{[23]}$ on the other hand, determined that the sample size should be at least 200 cases. In this study, a total of 400 nursing students from Sari, Iran were thus recruited over a two-month span from April through May 2016. Required inclusion criteria were: (i) ability to read and write in the Persian language, (ii) absence of co-morbid psychiatric problems (such as diagnosis of schizophrenia, post-traumatic stress or other anxiety disorders, dementia, or depression) and (iii) absence of physical problems such as symptoms that could restrict research engagement. Rationales for barring nursing students who reported histories of clinical depression and/or anxiety disorders were to safeguard that participants were free of mental health limitations that potentially would contribute to the manifestation of death anxiety. Participants were also excluded if they reported addiction disorders to substances such as alcohol or other drugs.

The students completed a baseline demographic questionnaire that ascertained information about age, sex, and other factors. The TDAS was completed at baseline and was repeated two weeks later. Before translation of the TDAS into Persian, authorization to conduct this research was derived. ${ }^{[24]}$ The World Health Organization recommendations were utilized for instrument translation. ${ }^{[25]}$ The TDAS incorporates 15 items that are calculated utilizing a five-point Likert format $(1=$ completely disagree $) ;(5=$ completely agree). 


\subsection{Evaluation of construct validity}

The factor structure of the Persian TDAS was evaluated by completing a principal axis factoring exploratory factor analysis (EFA) followed by a Promax rotation with SPSS 22 (SPSS Inc., Chicago, IL, USA) to determine construct validity. The Kaiser-Meyer-Olkin (KMO) test and the Bartlett's test of sphericity were utilized for assessing sample suitability with the factor analytic model. Factor numbers were decided with attention to both eigenvalues with the scree plots. If the absolute loading values of individual items were .3 or greater, they were determined to be appropriate. Any eigenvalues that were less than one remained disregarded. ${ }^{[26]}$

The factor structure obtained from the EFA were subsequently evaluated by utilizing confirmatory factor analysis (CFA) utilizing AMOS 19. In line with experts' recommendations, the Adjusted Goodness of Fit Index (AGFI), $\chi^{2}$ goodness-of-fit index (GFI), Normed fit index (NFI), TuckerLewis index(TLI), Root Mean Square Error of Approximation (RMSEA), Parsimonious Comparative Fit Index (PCFI), and the chi-square were separated with degrees of freedom values $\left(\chi^{2} / \mathrm{df}\right){ }^{[27]}$

For second-order factor analysis, it is presumed that extracted latent variables in the first stage are indicators of a different conceptual level. Thus, second-order factor analyses can represent concepts that are more general at upper levels. ${ }^{[28]}$ Some studies indicated that the TDAS displays components of the more general concept. ${ }^{[29,30]}$ Moreover, extracted dimensions of the death anxiety construct express the more common general concepts of this scale. Therefore, a secondorder CFA was performed after the first-order factor analysis.

Convergent validity was evaluated by approximating Average Variance Extracted (AVE) and construct reliability. To institute convergent validity, the constructs AVE must surpass .5 and also be lower than the construct reliability. ${ }^{[31-34]}$

\subsection{Reliability evaluation}

The reliability of the Persian TDAS was first evaluated by assessment of internal consistency and by computing the Cronbach's alpha $(\alpha)$, McDonald Omega $(\Omega)$ and Theta $(\theta)$, Cronbach's alpha is a measure of internal consistency, that refers to how closely a set of items are related as a whole. Thus, it is a measure of scale reliability. McDonald's is also a reliability coefficient that is similar to Cronbach's Alpha. However, a main advantage of Omega,compared to Cronbach's alpha, is that it adds the advantage of taking into account the strength of association between items in an instrument when conducting factor analysis. Theta is also essential in the process of determining reliability given an essential role of evaluating factors in descending order given variance

Published by Sciedu Press in the specific scale construction. Coefficients for total concurrence of discrete items and domains. ${ }^{[34]}$ It was found that Omega provided the highest estimate of reliability. ${ }^{[35]}$ Reliability of .7 or higher demonstrates internal consistency that is acceptable. ${ }^{[36]}$ Given relevant indicators were satisfactory, construct reliability of the factors were then tested with values between .6 and .7 deemed acceptable. ${ }^{[37,38]}$ Intra-class correlation coefficients (ICC) were used to determine the test-retest reliability of the TDAS across a period of two weeks using a two-way mixed ICC for complete agreement at the level of individual items. The findings were interpreted as follows: 0-.20 as low, .21-.40 as fair, .41-.60 as moderate, $.61-.80$ as substantial, and $.81-1.0$ as excellent. ${ }^{[39]}$

\subsection{Multivariate normality and outliers}

We checked for outliers, skewness, and kurtosis utilizing univariate distributions. Multivariate distributions were tested for normality and multivariate outliers. ${ }^{[40]}$ Multivariate normality is often assessed by utilization of Mardia's coefficient for kurtosis. Mardia's coefficients larger than 8 were used as a normal distribution deviation indicator. ${ }^{[27]}$ The Mahalanobis distance was used to assess for multivariate outliers. ${ }^{[41]}$ Such outliers were calculated by distances with a $p<.001 .^{[42]}$

\subsection{Ethical matters}

The study was granted approval by the appropriate Medical Sciences Ethics Committee (Ethics Code: IR.MAZUMS.REC 96.122). All nursing students who participated were educated about the study aims, procedures, and its voluntary nature. Informed signed consent was then obtained from all participants. Confidentiality of survey data was maintained by assignation of a coded number to de-identify volunteers.

\section{Results}

\subsection{Demographic data}

Socio-demographic data from the study sample are displayed in Table 1. As depicted, participants were composed of 92 (23\%) males, 308 (77\%) females, with age means of 21.9 ( $\mathrm{SD}=3.58)$, who were mostly Bachelor of Science students $(\mathrm{n}=336,84 \%)$. The demographics Omega are reflective of the socio-demographic profile of university nursing students in Iran.

\subsection{Construct validity}

Table 2 depicts findings from executing the principal axis factoring EFA of the TDAS. The KMO was .853, and the Bartlett's sphericity tests were significant $(p<.001,940.312$, $\mathrm{df}=66$ ) indicating sufficient sampling. A scree plot, depicted in Figure 1 evaluated factors with eigenvalue larger than one, 
and EFA extracted two factors entailing 15 items together that explained $60.164 \%$ of the variance. All items had factor loadings larger than .4.

Table 1. Socio-demographic profiles of the participants

\begin{tabular}{ll}
\hline Characteristic & $\mathbf{n}(\%)$ \\
\hline Sex & $92(23)$ \\
Male & $308(77)$ \\
Female & \\
Educational Status & $336(84)$ \\
BSN student & $64(16)$ \\
Master's student & \\
Marital status & $386(96.5)$ \\
Single & $14(3.5)$ \\
Married & \\
Residence & $165(41.2)$ \\
Urban area & $186(46.5)$ \\
Small town & $49(12.3)$ \\
Rural & \\
Employment status & $12(3)$ \\
Full time & $26(6.5)$ \\
Part time & $362(90.5)$ \\
Not employed & Mean (SD) \\
Characteristic & $21.9(3.58)$ \\
Age &
\end{tabular}

Next, in the first-order confirmatory factor analysis, the factor structure derived with EFA was tested for validation utilizing maximum likelihood CFA. Given modification indexes, one pair of measurement errors (items $9 ; 11$ ) were permitted to co-vary. Figure 2 depicts the final model following studying modification parameters for sources of model misfits. The findings from performing CFA on the TDAS specified as a two factors comprising of 15 items suggesting a good fit $\left(\chi^{2}\right.$ $(179, \mathrm{~N}=200)=111.387, p<.001 ; \chi^{2} / \mathrm{df}=2.652$, GFI $=$ $.906, \mathrm{AGFI}=.852, \mathrm{NFI}=.877$, Comparative Fit Index $=.919$, $\mathrm{TLI}=.894$, Incremental Fit Index $=.920$, Root Mean Square Residual $=.093$ and $\mathrm{RMSEA}=.091(90 \% \mathrm{CI}=.071-.112))$.

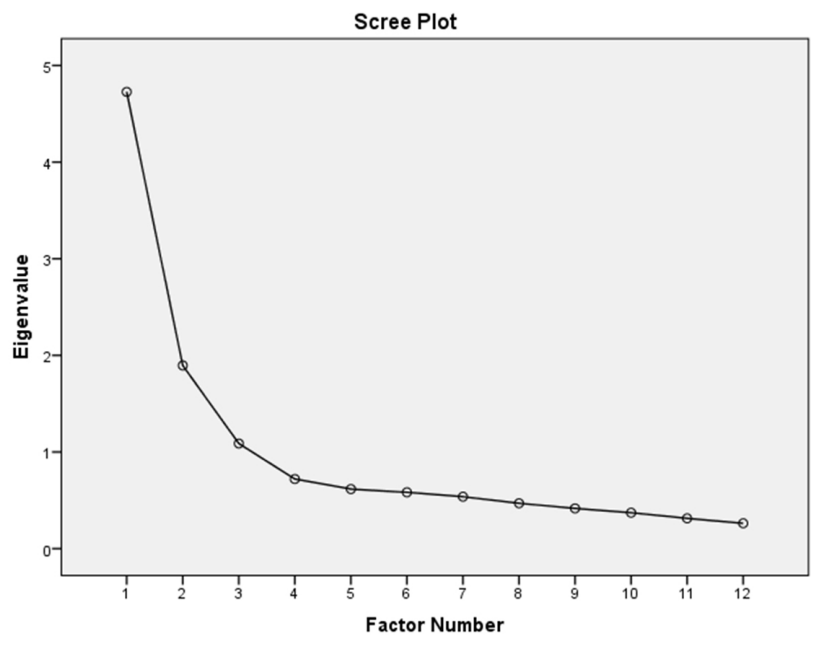

Figure 1. Scree plot for the exploratory factor analysis (EFA) of the death anxiety scale (DAS)

Table 2. Factor analysis for the Persian version of death anxiety scale in Iranian nursing students

\begin{tabular}{|c|c|c|c|c|c|}
\hline $\begin{array}{l}\text { Factors } \\
\text { name }\end{array}$ & Items & Loading & $* h^{2}$ & $\begin{array}{l}\% \text { of } \\
\text { Variance }\end{array}$ & Eigenvalues \\
\hline \multirow{7}{*}{$\begin{array}{l}\text { Fear of loss } \\
\text { of life }\end{array}$} & Q10. The subject of life after death troubles me greatly & .842 & .642 & \multirow{7}{*}{32.583} & \multirow{7}{*}{3.854} \\
\hline & Q9. I fear dying a painful death & .837 & .630 & & \\
\hline & Q12. I often think about how short life really is & .756 & .506 & & \\
\hline & Q11. I am really scared of having a heart attack & .703 & .499 & & \\
\hline & Q15. I feel that the future holds nothing for me to fear & .588 & .498 & & \\
\hline & Q7. The thought of death never bothers me & .500 & .554 & & \\
\hline & Q8. I am often distressed by the way time flies so rapidly & .461 & .371 & & \\
\hline \multirow{4}{*}{$\begin{array}{l}\text { Fear to face } \\
\text { death }\end{array}$} & Q5. I am not at all afraid to die & -.763 & .494 & \multirow{4}{*}{27.581} & \multirow{4}{*}{3.034} \\
\hline & Q1. I am too afraid to die & .694 & 639 & & \\
\hline & Q3. It doesn't make me nervous when people talk about death & .660 & 602 & & \\
\hline & Q4. I dread to think about being compelled to have an operation & .646 & .310 & & \\
\hline
\end{tabular}

$* h^{2}$ : Communalities

The factors of TDAS were assessed separately after completing the first-order CFA. The second-order CFA was used to assess whether all the factors are placed in the general context of the TDAS. The fitness indexes of the second-order CFA in comparison with the pre and after modification of the first-order CFA are shown in Table 3. Figure 3 shows the structural model of TDAS with the standardized coefficients loading factor.

\subsection{Reliability}

Cronbach's alpha, Theta, McDonald Omega, and construct reliability of Factor 1 and Factor 2 demonstrated good reliability and internal consistency for both factors (see Table 4). The average measure ICC was .785 with a $95 \%$ confidence interval between .739 to $.826(\mathrm{~F}(200)=17.722, p<$ .001). Further, the findings demonstrated that the construct AVE surpassed .5 and the construct reliability was larger than 
its AVE, satisfying the necessary parameters of convergent validity.

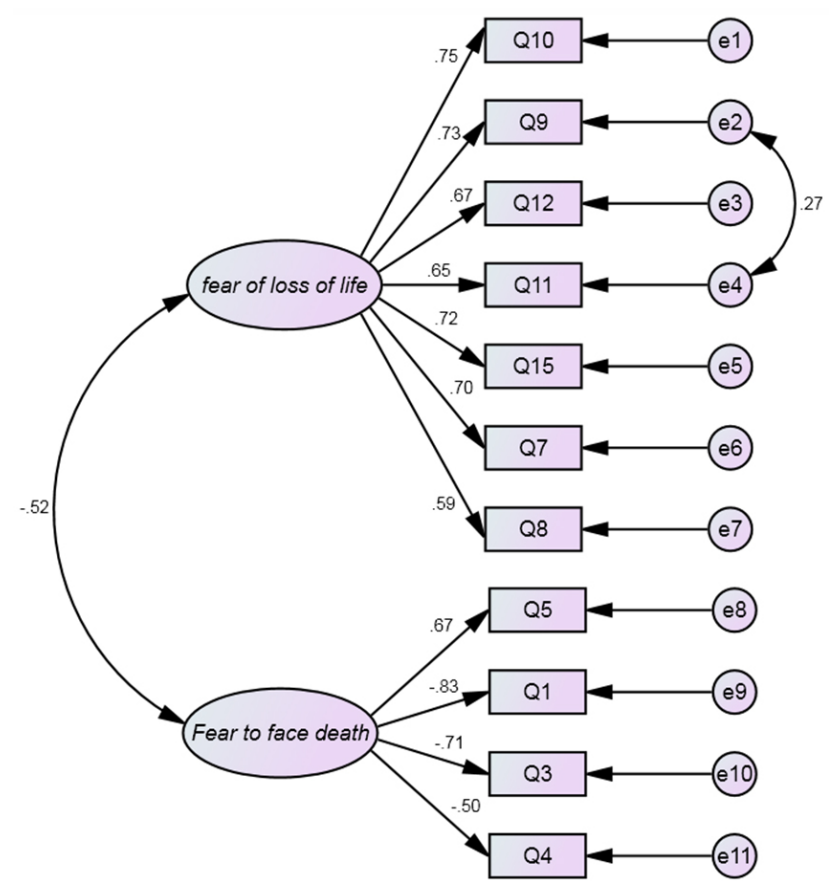

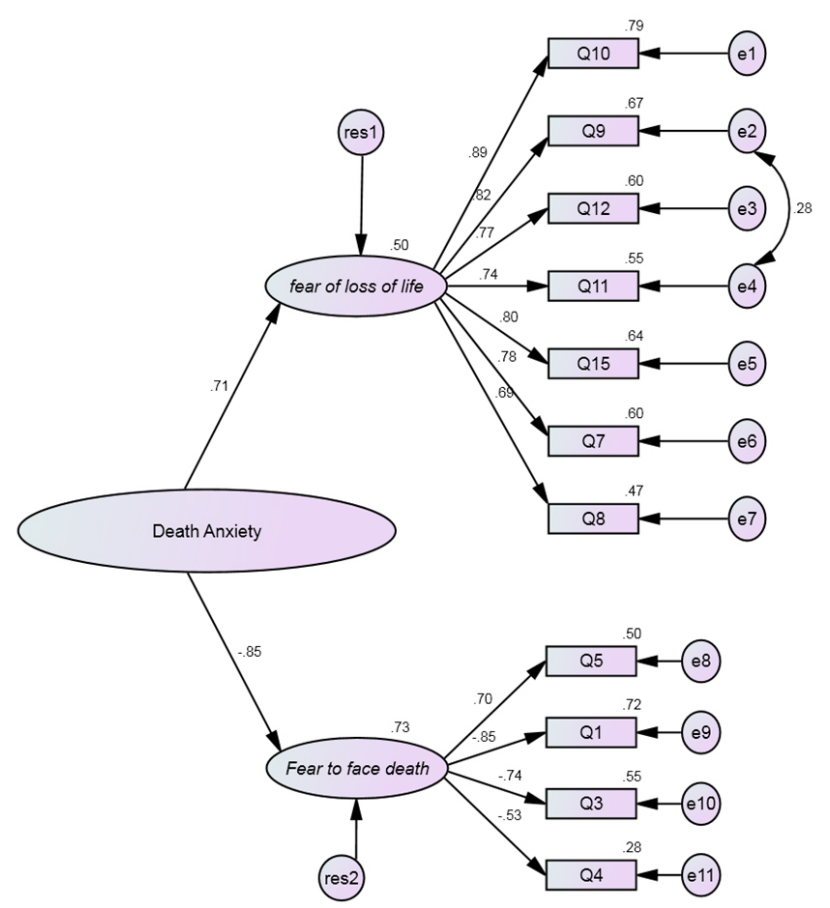

Figure 3. The final model of the second order death anxiety factor model

Figure 2. The final model of the first order death anxiety factor model

Table 3. Model Fitness Indices of the first and second order CFA

\begin{tabular}{|c|c|c|c|c|c|c|c|c|c|c|}
\hline Index CFA & $\chi^{2}$ & df & $p$-value & CMIN/DF & RMSEA & PCFI & PNFI & AGFI & IFI & CFI \\
\hline First order & 111.387 & 42 & $<.001$ & 2.652 & .091 & .694 & .660 & .852 & .920 & .919 \\
\hline Second order & 97.986 & 41 & $<.001$ & 2.390 & .083 & .696 & .665 & .873 & .934 & .933 \\
\hline
\end{tabular}

Note. Acceptable Index: Root Mean Square Error of Approximation (RMSEA) (>.08); Parsimonious Comparative Fit Index (PCFI), PNFI (>.5); Adjusted Goodness of Fit Index (AGFI), Incremental Fit Index (IFI), Comparative Fit Index [CFI (>.9)]; and Comparative Minimum/Degrees of Freedom [CMIN/DF $(>3=$ good, $>5=$ acceptable $)$.

Table 4. Construct validity and reliability results and the fornell larcker criterion

\begin{tabular}{llllll}
\hline & $\boldsymbol{\alpha}$ & $\boldsymbol{\theta}$ & $\boldsymbol{\Omega}$ & $\mathbf{C R}$ & $\mathbf{A V E}$ \\
\hline Factor 1: fear of loss of life & .865 & .888 & .788 & .883 & .678 \\
Factor 2: Fear to face death & .605 & .893 & .758 & 768 & .698
\end{tabular}

Note. $\alpha$ : Cronbach's alpha coefficients, $\theta$ : Theta Coefficient, $\Omega$ : McDonald's

Omega Coefficient, CR: Construct reliability, AVE: Average variance extracted

\section{Discussion}

Although death anxiety is recognized to be an important concept that affects nurses who are faced with death encounters in the workplace, there are limited assessment strategies to measure this phenomenon in Iranian nursing students. Thus, the current inquiry focused on evaluating validity and reliability of the TDAS with a sample of Iranian nursing students. The results revealed the TDAS to have a two-factor structure that included 'fear of loss of life' and 'fear of facing death'. These two factors explained a significant share $(47.59 \%)$ of the total variance. Psychometric methodology researchers have stated that the extraction of factors is suitable when the explained variance falls within the range of $50 \%$ to $60 \%$ in psychometric analysis. ${ }^{[37]}$ Our study differs from previous studies in terms of the number of factors extracted, the distinctive nature of the sample selection, and the unique study environment. ${ }^{[19,21]}$

Researchers have reported that fear of loss of life amongst the factors affecting death anxiety in other samples including caregivers of cancer patients. ${ }^{[21]}$ Such fears relative to loss of life are often activated by personal encounters with patients facing life threatening illnesses. Cognitions associated with death and the anxious preoccupations that follow are common in all societies and cultures, but culturally diverse social 
and religious institutions manage this awareness in varied modes. ${ }^{[6]}$ Further, it is recognized that cultural, cognitive, and emotional factors contribute to an individual's attitude towards death. ${ }^{[3]}$ Unique personal and environmental factors may stimulate thoughts of death, and fear and anxiety can arise from the psychological impact. ${ }^{[20]}$

In this study, after the removal of outlier data, weak markers, and evaluation of the natural data distribution, the fitness of structural factors of the TDAS were assessed and the most common indicators of the model fit were evaluated. The model fit results were tested for all indicators and the item factor loadings were larger than 0.4 ranges, indicating that they had a minimum of acceptable loading factors. Therefore, conferring findings from the confirmatory factor analysis, the observed indices were corroborated and fit indices had solid standard levels. Although many studies used EFA for validating TDAS, this research used CFA in validating the scale. In the final TDAS model, there were correlations noted between the measurement errors of items 9 and 11. Correlated measurement errors may occur in circumstances where variables cannot be identified plainly or measured exactly, which in turn affects item responses. The type of measurement, such as self-reported assessment, may contribute to such error. ${ }^{[43]}$ For example, measurement errors can result from similar meanings of words and phrases in positively and negatively toned declarations. ${ }^{[41]}$ Based on feedback attained from the participants in this study, the structure of these two TDAS items may have similar meaning and/or underlying concepts contributing to the considerable measurement error.

A second-order confirmatory factor analysis was done utilizing structural equation modeling to achieve accuracy by extracting the meaningful data. ${ }^{[42]}$ With this methodology it is assumed that latent variables in the shared variance are due to one or higher order factors and the construct contains two levels. ${ }^{[28]}$ Structural equation modeling is the most appropriate approach to investigate this structure due to its ability to

\section{REFERENCES}

[1] Neimeyer RA. Death anxiety handbook: Research, instrumentation, and application: Taylor \& Francis; 2015. https ://doi .org/10.4 324/9781315800813

[2] Sharif Nia H, Lehto RH, Ebadi A, et al. Death anxiety among nurses and health care professionals: A review article. I J Comm based nurs midwif. 2016; 4(1): 2.

[3] Lehto R, Stein K. Death anxiety: an analysis of an evolving concept. Res Theory NursPractice: Int J. 2009; 23: 23-41. PMid:19418886 https://doi.org/10.1891/1541-6577.23.1.23 represent and introduce the first-level structures as latent variables. Final model TDAS structures had suitable convergent and divergent validity. With convergent validity, the items of the intended structure are proximal sharing variance with each other. With divergent validity, intended structure or hidden factor items are removed entirely. ${ }^{[37]}$ In the current study, the TDAS instrument reliability was suitable as evidenced by the high Cronbach's alpha demonstrating scale internal consistency. TDAS reliabilities using Cronbach's alpha has been reported in several studies from 0.73 to $0.89 .^{[44-46]}$ Other research ${ }^{[45]}$ tested the reliability of this scale utilizing ICC and "split-half" methodology which were reported to be 0.87 and 0.59 , and $0.57 .^{[47]}$ Construct reliability was also demonstrated to be satisfactory in the study.

\section{Conclusions}

In Iran, there are distinct geographical areas that vary significantly in sociocultural norms. Hence, it is essential that studies evaluating the Persian version of TDAS are replicated in other Iranian nursing student samples. It is recognized that death anxiety can be a significant factor that impacts mental health in nursing students and practicing nurses. The study determined satisfactory measurement properties with the TDAS factor structure for a sample composed of nursing students from Iran. Although continuing research is recommended, the scale can be utilized as an effective dependable instrument for assessing nursing student death anxiety in Iranian samples. The TDAS is recognized to be a valid instrument in other international nursing groups. ${ }^{[46]}$ This study adds to a growing body of nursing literature that has evaluated this measure in global populations.

\section{ACKNOWLEDGEMENTS}

The authors are grateful and appreciate the nursing students who ensured that the research was achievable.

\section{CONFlicts of INTEREST Disclosure}

The author declares that there is no conflict of interest.
[4] Neimeyer RA, Wittkowski J, Moser RP. Psychological research on death attitudes: An overview and evaluation. Death Stud. 2004; 28(4): 309-40. PMid:15129688 https://doi .org/10.1080/07481180 490432324

[5] Haldorsen H, Bak NH, Dissing A, et al. Stress and symptoms of depression among medical students at the University of Copenhagen. Scan J Pub Health. 2014; 42(1): 89-95. PMid:23999855 https://doi.org/10.1177/1403494813503055

[6] Moudi S, Bijani A, Tayebi M, et al. Relationship between death anxiety and mental health status among nurses in hospitals affiliated to Babol University of Medical Sciences. J Babol Univ Med Sci. 2017; 
19(2): 47-53.

[7] Peters L, Cant R, Payne S, et al. How death anxiety impacts nurses' caring for patients at the end of life: a review of literature. Open Nurs J. 2013; 7: 14. PMid:23400515 https://doi.org/10.2174/18 74434601307010014

[8] Nienaber K, Goedereis E. Death anxiety and education: A comparison among undergraduate and graduate students. Death Stud. 2015; 39(8): 483-90. PMid:26019002 https ://doi.org/10.1080/07 481187.2015 .1047057

[9] Gomez-Urquiza JL, Aneas-Lopez AB, Fuente-Solana EI, et al. Prevalence, risk factors, and levels of burnout among oncology nurses: A systematic review. Oncol Nurs sForum. 2016; 43(3): E104-20. PMid:27105202 https://doi.org/10.1188/16. ONF .E104-E120

[10] Crowe C. Burnout and self-considerations for oncology professionals. J Pain Man. 2015; 8(3): 191-5.

[11] Breen LJ, O'connor M, Hewitt LY, et al. The "specter" of cancer: Exploring secondary trauma for health professionals providing cancer support and counseling. Psychol Serv. 2014; 11(1): 60-7. PMid:24079353 https ://doi .org/10.1037/a0034451

[12] Back AL, Steinhauser KE, Kamal AH, et al. Building resilience for palliative care clinicians: an approach to burnout prevention based on individual skills and workplace factors. J Pain Sym Manag. 2016; 52(2): 284-91. PMid:26921494 https ://doi.org/10.1016/j . jpainsymman.2016.02.002

[13] Fetter KL. We grieve too: One inpatient oncology unit's interventions for recognizing and combating compassion fatigue. Clin J Oncol Nurs. 2012; 16(6): 559. PMid:23178347 https ://doi .org/10.1 188/12. CJON. 559-561

[14] Halbesleben JR, Wakefield BJ, Wakefield DS, et al. Nurse burnout and patient safety outcomes: nurse safety perception versus reporting behavior. West J Nurs Res. 2008; 30(5): 560-77. PMid:18187408 https://doi.org/10.1177/0193945907311322

[15] Lee YM, Jung KA, Son M. Attitudes towards death and euthanasia among nurses and nursing students: in convergence era. J Digital Converg. 2015; 13(6): 213-24. https ://doi .org/10.14400/JDC .2015 .13 .6 .213

[16] Ko GH, Cho IS. Attitudes towards death and euthanasia among nurses and general population. J Korea Contents Assn. 2015; 15(3): 229-40. https://doi.org/10.5392/JKCA.2015.15.03.229

[17] Templer DI. The construction and validation of a Death Anxiety Scale. J Gen Psychol. 1970; 82(2): 165-77. PMid:4394812 https://doi.org/10.1080/00221309.1970.9920634

[18] Naderi F, Esmaili E. Collet-Lester Fear of Death Scale validation and gender-based comparison of death anxiety, suicide ideation and life satisfaction in university students. J Appl Scien. 2009; 9(18): 3308-16. https://doi .org/10.3923/jas . 2009.3308.3316

[19] Sharif Nia H, Ebadi A, Lehto RH, et al. Reliability and validity of the Persian version of Templer Death Anxiety Scale-extended in veterans of Iran-Iraq warfare. Iran J Psychiat Behav Sci. 2014; 8(4): 29.

[20] Soleimani MA, Yaghoobzadeh A, Bahrami N, et al. Psychometric evaluation of the Persian version of the Templer's Death Anxiety Scale in cancer patients. Death Stud. 2016; 40(9): 54757. PMid:27259574 https : //doi.org/10.1080/07481187. 201 6.1187688

[21] Soleimani MA, Bahrami N, Yaghoobzadeh A, et al. Validity and reliability of the Persian version of Templer Death Anxiety Scale in family caregivers of cancer patients. Iran J Nurs Midwif Res. 2016; 21(3): 284. PMid:27186206 https ://doi.org/10.4103/1735 $-9066.180390$

Published by Sciedu Press
[22] Plichta SB, Kelvin EA, Munro BH. Munro's Statistical Methods for Health Care Research: Wolters Kluwer Health/Lippincott Williams \& Wilkins; 2013.

[23] MacCallum RC, Widaman KF, Zhang S, et al. Sample size in factor analysis. Psychol Meth. 1999; 4(1): 84. https ://doi.org/10.1 037/1082-989X.4.1.84

[24] Templer D. DeathAnxiety Scale 2012. Available from: http://do nalditempler.com/assets/templer_1.pdf

[25] World Health Organization. Process of translation and adaptation of instruments. 2009.

[26] Saggino A, Kline P. Item factor analysis of the Italian version of the Death Anxiety Scale. J Clini Psychol. 1996; 52(3): 329 33. https : //doi .org/10.1002/(SICI) 1097-4679(199605) 5 $2: 3<329:$ : AID- JCLP11>3.0.C0;2-K

[27] Pahlevan Sharif S, Mostafiz I, Guptan V. Structural Equation Modeling in Nursing Research: A Systematic Review. Nurse Res. Forthcoming.

[28] Gatignon H. Statistical analysis of management data: Springer US; 2013.

[29] Maltby J, Day L. Religious orientation and death obsession. J Genetic Psychol. 2000; 161(1): 122-4. PMid:10705589 https: //doi.org/10.1080/00221320009596699

[30] Cella DF, Tross S. Death anxiety in cancer survival: a preliminary cross-validation study. J Perso Assess. 1987; 51(3): 45161. PMid:3656059 https ://doi.org/10.1207/s15327752jpa 5103_12

[31] Cohen AB, Pierce Jr JD, Chambers J, et al. Intrinsic and extrinsic religiosity, belief in the afterlife, death anxiety, and life satisfaction in young Catholics and Protestants. J Res Pers. 2005; 39(3): 307-24 https ://doi.org/10.1016/j.jrp.2004.02.005

[32] Fornell C, Larcker D. Evaluating structural equation models with unobservable variables and measurement error. J Marketing Res. 1981; 18(1): 39-50. https://doi.org/10.1177/0022243781018001 04

[33] Pahlevan SS, Mahdavian V. Structural Equation Modeling by the Use of AMOS. Tehran: Fazel; 2015.

[34] Sb J, Gudaganavar N. Effect of varying sample size in estimation of reliability coefficients of internal consistency. Webmed Central [Internet]. 2011 Feb 23 [cited 2011 Dec 22].

[35] Carmines EG, Zeller RA. Reliability and Validity Assessment: SAGE Publications; 1979. https ://doi .org/10.4135/978141298564 2

[36] Jorritsma W, de Vries GE, Dijkstra PU, et al. Neck pain and disability scale and neck disability index: validity of Dutch language versions. Eur Spine J. 2012; 21(1): 93-100. PMid:21814745 https : //doi .org/10.1007/s00586-011-1920-5

[37] Hair J, Black W, Babin B, et al. Multivarite Data Analysis. 7th ed Upper Saddle River, NJ: Prentice Hall; 2010.

[38] Nunnally J, Bernstein I. Psychometric Theory. 3rd ed. New York: McGraw-Hill; 1994.

[39] Landis JR, Koch GG. The measurement of observer agreement for categorical data. Biometrics. 1977; 33(1): 159-74. https: //doi.org/10.2307/2529310

[40] Sharif Nia H, Pahlevan Sharif S, Goudarzian AH, et al. An evaluation of psychometric properties of the Templer's Death Anxiety Scale-Extended among a sample of Iranian chemical warfare veterans. Hayat. 2016; 22(3): 229-44.

[41] Harrington D. Confirmatory Factor Analysis: Oxford University Press, USA; 2008. https ://doi .org/10.1093/acprof : oso/97 80195339888.001 .0001

[42] Tabachnick BG, Fidell LS. Using Multivariate Statistics: Pearson Education; 2013 
[43] Munro B, editor. Statistical methods for health care research. Lippincott Williams \& Wilkins. 2005.

[44] Thorson JA, Powell F. A revised death anxiety scale. Death Stud. 1992; 16(6): 507-21. https://doi.org/10.1080/0748118920 8252595

[45] Tavakoli MA, Ahmadzadeh B. Investigation of validity and reliability of templer death anxiety Scale. Thought Beh Clin Psychol. 2011; 6(21): 72-80.
[46] Tomas-Sabado J, Gomez-Benito J. Psychometric properties of the Spanish form of Templer's death anxiety scale. Psychol Rep. 2002; 91(3 Pt 2): 1116-20. PMid:12585522 https ://doi .org/10. 246 $6 /$ pr0.2002.91.3f.1116

[47] Abdel-Khalek AM. The development and validation of an Arabic form of the STAI: Egyptian results. Pers Indiv Differ. 1989; 10: 277-85. https://doi .org/10.1016/0191-8869(89)90100-1 